\title{
PROPOSTA DE INTRODUÇÃO DO MODELO DE PRODUÇÃO DE CARVÃO VEGETAL UTILIZADO NO BRASIL EM MOÇAMBIQUE COMO FORMA DE REDUÇÃO DE IMPACTOS AMBIENTAIS DERIVADOS DO PROCESSO
}

\author{
Manuel Pastor Francisco Conjo ${ }^{1}$ \\ David Benjamim Chichango ${ }^{2}$ \\ Octávio Manuel de Jesus ${ }^{3}$ \\ Paulo de Paula e Souza ${ }^{4}$
}

RESUMO: A importância do carvão vegetal demonstra-se inquestionável na vida de bilhões de pessoas um pouco por todo mundo, mas por outro lado, desdobram-se esforços na busca por fontes de energia capazes de suprir as necessidades com impacto ambiental reduzido, com maior retorno econômico e maior valorização do trabalho dos envolvidos. Este estudo propõe de entre as duas realidades, modelo brasileiro versos moçambicano, recomendar a introdução do modelo ambiental e econômico eficiente de produção de carvão vegetal em Moçambique, para tal, compara-se os processos produtivos dos dois países, a partir de modelos utilizados tanto no Brasil como Moçambique, utilizando-se uma metodologia simples qualitativa, onde se faz uma análise de variáveis que demonstram aspetos fortes, oportunidades, fraquezas e ameaças (matriz FOFA). Usou-se também a técnica de observação que possibilitou juntamente com a analise fofa obter os resultados da pesquisa, onde se apurou que introduzindo o modelo brasileiro de produção de carvão vegetal em Moçambique poderia se reduzir o risco ambiental de queimadas descontrolada, desflorestamento, erosão dos solos

\footnotetext{
${ }^{\mathrm{I}}$ Doutorando em Ciência Florestal pela Universidade Federal de Viçosa - Minas Gerais - Brasil Instituição: Universidade Pedagógica de Maputo/Universidade Federal de Viçosa. Mestrado em Gestão Ambiental pela Universidade Pedagógica de Maputo - Moçambique. Bacharel e Licenciado em Ensino de Geografia pela Universidade Pedagógica de Maputo Moçambique. Técnico Superior em Higiene e Segurança no Trabalho e Meio Ambiente pela Ensine Moçambique. E-mail: pastorconjooo7@gmail.com

${ }^{2}$ Mestrando em Gestão Ambiental, Faculdade de Ciências da Terra e Ambiente, Universidade Pedagógica de Maputo, Moçambique. Prof. de Geografia, Licenciado em Ensino de Geografia, Faculdade de Ciências da Terra e Ambiente, Universidade Pedagógica de Maputo, Moçambique. Email: davidchitlhango@gmail.com.

${ }^{3}$ Doutor em Ciências Pedagógicas, Moçambicano, funcionário do Ministério da Ciência, Tecnologia e Ensino Superior. Mestrado em Didáctica da Geografia, Menção Geografia Económica e Social, no Instituto Superior Pedagógico "Enrique José Varona” em Havana-Cuba. Licenciatura em Ensino de História e Geografia, no Instituto Superior Pedagógico de Maputo-Moçambique. Docente na Universidade Pedagógica de Maputo (desde 2006), categoria Professor Auxiliar, nas seguintes cadeiras científicas: Gestão Ambiental e Educação Ambiental; Didáctica de Geografia; Geografia de Moçambique I e II; Temas de Actualidade em Geografia Física Geral e Geografia Física Regional. Membro de Júri, Supervisor e Arguente nas Defesas de Monografias, Dissertações em Havana-Cuba e Maputo- Moçambique. Supervisor das teses de Doutoramento em Moçambique. E-mail: Octaviomzoor@yahoo.es.

${ }^{4}$ Mestrando em Gestão Ambiental, Faculdade de Ciências da Terra e Ambiente, Universidade Pedagógica de Maputo, Moçambique. Gestor. Licenciado em Gestão e Direito Privado. Unirsity of South Africa. Pos- Graduação em Administração de Empresas, University of South Africa. E-mail: ppsouza@hotmail.com.
} 
entre outros, para além de redução de desperdícios e obtenção de maiores ganhos econômicos. Acabou por se concluir que a migração para o modelo de produção de carvão utilizado no brasil em Moçambique será mais viável sob ponto de vista ambiental, social e econômico.

Palavras-chaves: Produção. Carvão vegetal. Ambiental. Brasil. Moçambique.

ABSTRACT: The importance of charcoal is unquestionable in the lives of billions of people all over the world, but on the other hand, efforts are being made in the search for energy sources capable of meeting the needs with reduced environmental impact, with greater economic return and greater appreciation of the work of those involved. This study proposes, between the two realities, the Brazilian model and the Mozambican model, to recommend the introduction of the efficient environmental and economic model of charcoal production in Mozambique. To this end, the production processes of the two countries are compared, based on models used both in Brazil as Mozambique, using a simple qualitative methodology, where an analysis of variables that demonstrate strong aspects, opportunities, weaknesses and threats is made (FOFA matrix). We also used the observation technique that made it possible, together with the fluffy analysis, to obtain the results of the research, where it was found that introducing the Brazilian model of charcoal production in Mozambique could reduce the environmental risk of uncontrolled burning, deforestation, erosion of the soils, among others, in addition to reducing waste and obtaining greater economic gains. It ended up concluding that the migration to the coal production model used in Brazil in Mozambique will be more viable from an environmental, social and economic point of view.

Keywords: Production. charcoal. Environmental. Brazil. Mozambique.

\section{INTRODUÇÃO}

O carvão vegetal é obtido a partir da queima ou carbonização de madeira, após esse processo resulta em uma substância negra de importante valor econômico e social.

No cotidiano o carvão vegetal é utilizado como combustível de aquecedores, lareira, churrasqueiras e fogões a carvão, além de abastecer alguns setores industriais, como as siderúrgicas para o caso brasil por exemplo.

Uma das formas de preservação do meio ambiente, é a conservação da natureza, quer seja pela proibição de extração de alguns recursos, extração racional e ou mesmo a redução no volume de extração, diminuindo a pressão que se exerce sobre os recursos naturais, o que por outro lado, reduz o volume de resíduos gerados para o meio ambiente (CONJO, 202I). Portanto, é extremamente importante que os países adotem medidas que visem lograr esse intento. 
Moçambique é um país com grande diversidade de florestas naturais da qual deriva a matéria prima para produção de carvão. Os combustíveis lenhosos são a principal fonte de energia usada pelos moçambicanos para suprir as suas necessidades de energia doméstica. Estima-se que pelo menos cerca de $80 \%$ de moçambicanos depende deste tipo de energia para confecção de alimentos, aquecimento da casa e confeitaria (ALBERTO, 2006). O processo de produção de carvão em Moçambique ainda é bastante arcaico e com potenciais riscos ambientais, assim como elevado nível de desperdícios.

Já no brasil, produção do carvão vegetal responde por cerca de I/3 da produção mundial, aqui utilizada em sua quase totalidade para a siderurgia, onde é feita por via de fornos para arborização (PINHEIRO et al., 2006). A produção de carvão vegetal com fornos representa mais de 70\% do sistema de produção de carvão vegetal no Brasil (RAAD; MELO; OLIVERIA, 2014). Hoje no Brasil, procura-se produzir somente com matéria prima proveniente de floresta plantada de eucalipto, que é uma das melhores opções para a produção de carvão vegetal, devido à rusticidade, produtividade e às características da madeira. As florestas plantadas de eucalipto, planejados e manejados, detém potencial de produzir árvores de troncos retos, uniformes e madeira com massa específica adequada para a obtenção de carvão de boa qualidade (PINHEIRO et al., 2006).

Diante do exposto, percebe-se o problema que Moçambique enfrenta com o tipo de produção artesanal que utiliza, o que suscita de uma melhoria quanto mais breve possível por representar grandes riscos para o meio ambiente e esgotamento da floresta nativa, que é a fonte de extração. O estudo tem por objetivo propor a introdução do modelo brasileiro de produção de carvão vegetal por fornos com recurso a madeira proveniente da floresta plantada em Moçambique. Os resultados foram alcançados por via de uma metodologia qualitativa por ter sido considerada a mais adequada aos objetivos propostos, tendo sido utilizado como instrumento para coleta de dados a observação (CONJO et al, 2021), e uso -se também analise de variáveis através da Matriz FOFA. ou SWOT, que segundo DAYCHOUW (2010), é uma ferramenta utilizada para fazer análises de cenário (ou análises de ambiente), sendo usada 
como base para a gestão e o planejamento estratégico. É um sistema simples para posicionar ou verificar a posição estratégica de qualquer cenário.

Acredita-se que o estudo seja relevante, uma vez que podemos perceber que a introdução do modelo de fornos na produção de carvão vegetal, o mesmo usado no Brasil, seria mais valia em Moçambique pelas razões já mencionadas acima.

\section{METODOLOGIA}

Os modelos de foram analisados com a finalidade de identificar a viabilidade de produção, os impactos ambientais, sociais e culturais da produção de carvão vegetal pelo processo usado no Brasil de carbonização utilizado fornos de alvenaria tipo "rabo quente "em comparação com o processo de carbonização usado em Moçambique em estufas feitas no solo a céu aberto, encobertadas com capim e areia (SANTOS e HATAKEYAMA, 2012).

Nesta abordagem buscamos por forma comparativa apresentar duas distintas realidades de produção do mesmo produto. Por via dessa comparação, propõe-se a introdução de um modelo em detrimento do outro, a partir das ilações advindas dos pontos fortes e oportunidades constatados com a introdução do modelo utilizado no Brasil em Moçambique. As ameaças e os pontos fracos advindos do uso do modelo de produção em vigor atualmente em Moçambique, irão servir para argumentar a necessidade de sua substituição por um modelo mais viável.

A comparação feita na pesquisa será realizada numa abordagem qualitativa, Campo da Pesquisa Social, que se apoia em dados sobre o mundo, que são construídos nos diferentes processos (CONJO et al, 2021).

\section{I.I. Procedimentos}

Com base em imagens ilustrando os processos de produção comparando as duas distintas realidades, constata-se aspetos de maior impacto que determinam a necessidade de substituição de um modelo por outro, destacando-se as principais vantagens da introdução do 
modelo de produção de carvão vegetal por via de fornos em Moçambique, conforme ilustrado nas Figuras i e 2.

Fig. I e 2 Esquemas de representação de modelos de produção de carvão vegetal Brasil versus Moçambique.

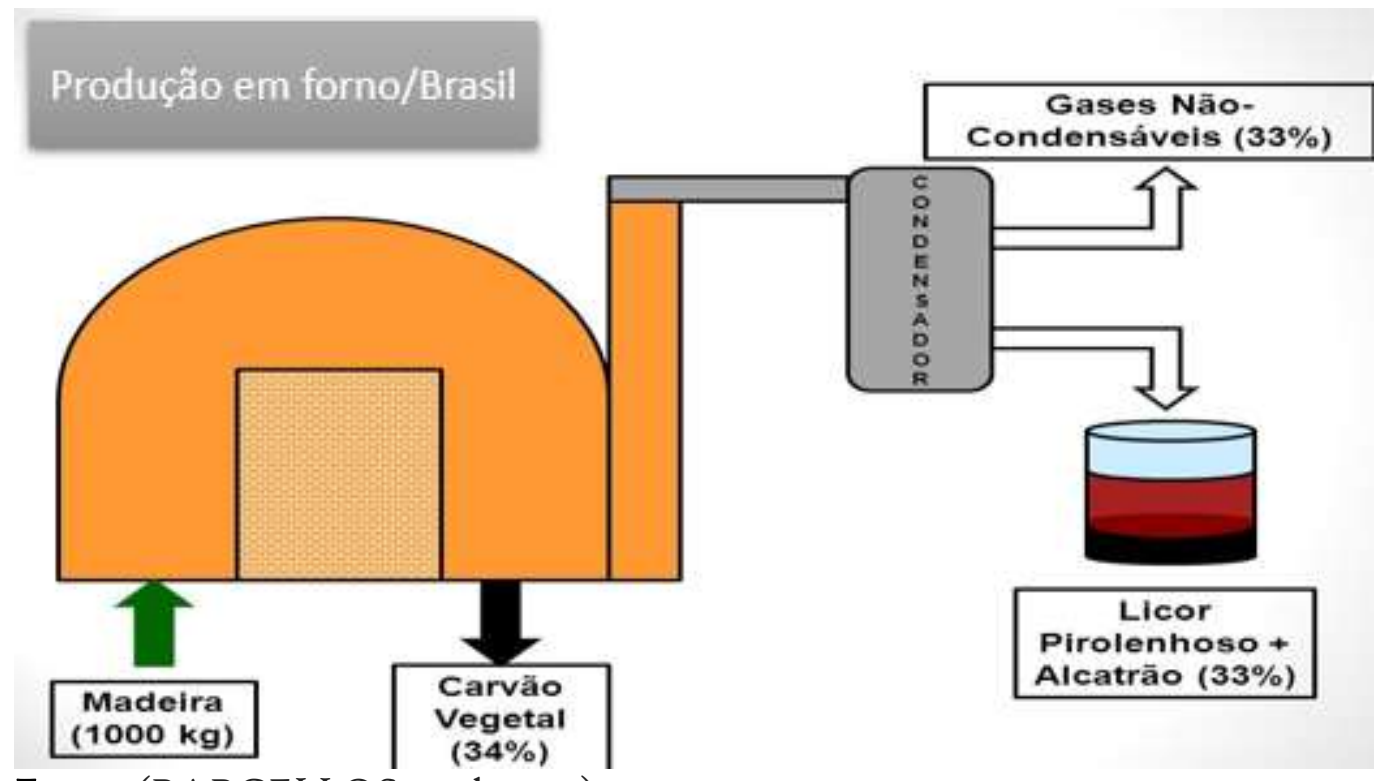

Fonte: (BARCELLOS et al, 2007)

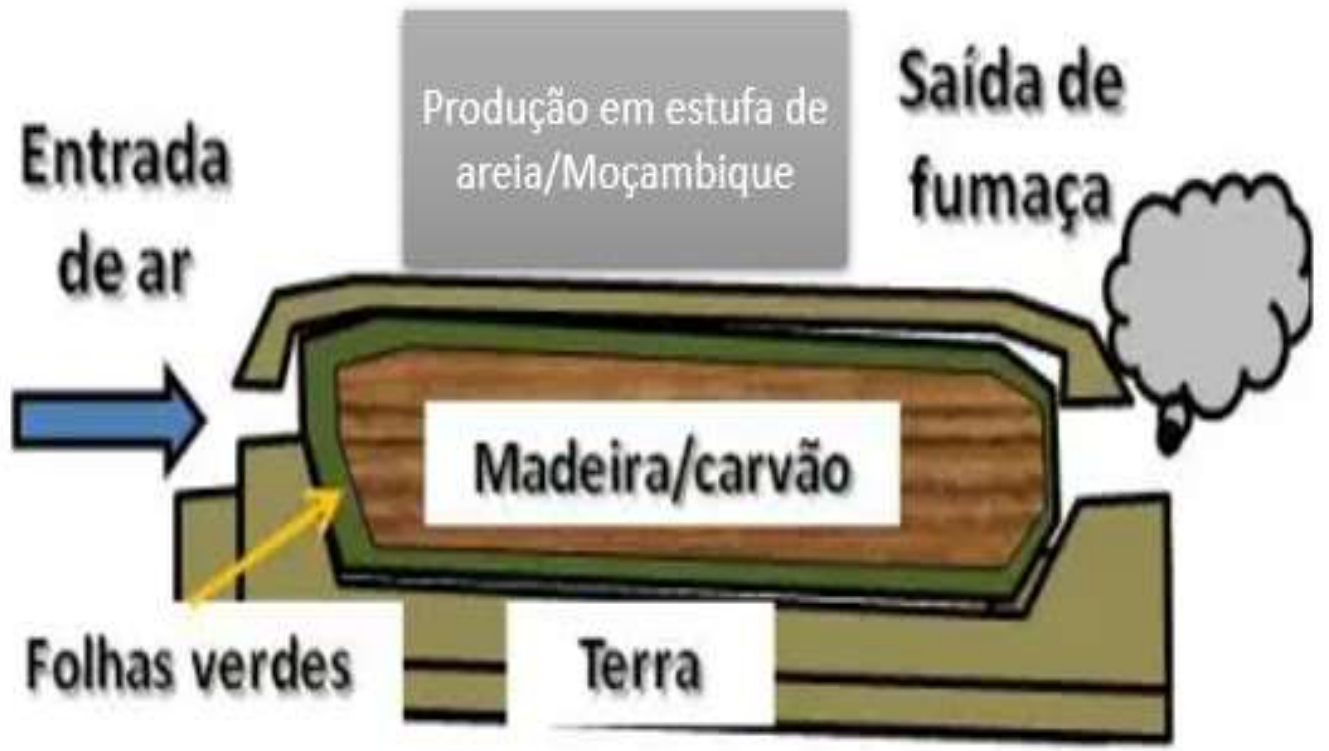

Fonte: (BARCELLOS et al, 2007) 
As imagens fotográficas apresentadas na Figura 3, irão trazer uma ilustração visual dos processos produtivos dos dois países em comparação, o que claramente evidencia a susceptibilidade de risco ambiental que o modelo tradicional/arcaico usado em Moçambique constitui e não só, é clara a ineficiência em termos de rapidez, volume e geração de resíduos.

Fig. 3 Ilustração de processo de produção de carvão no Brasil em Comparação com Moçambique

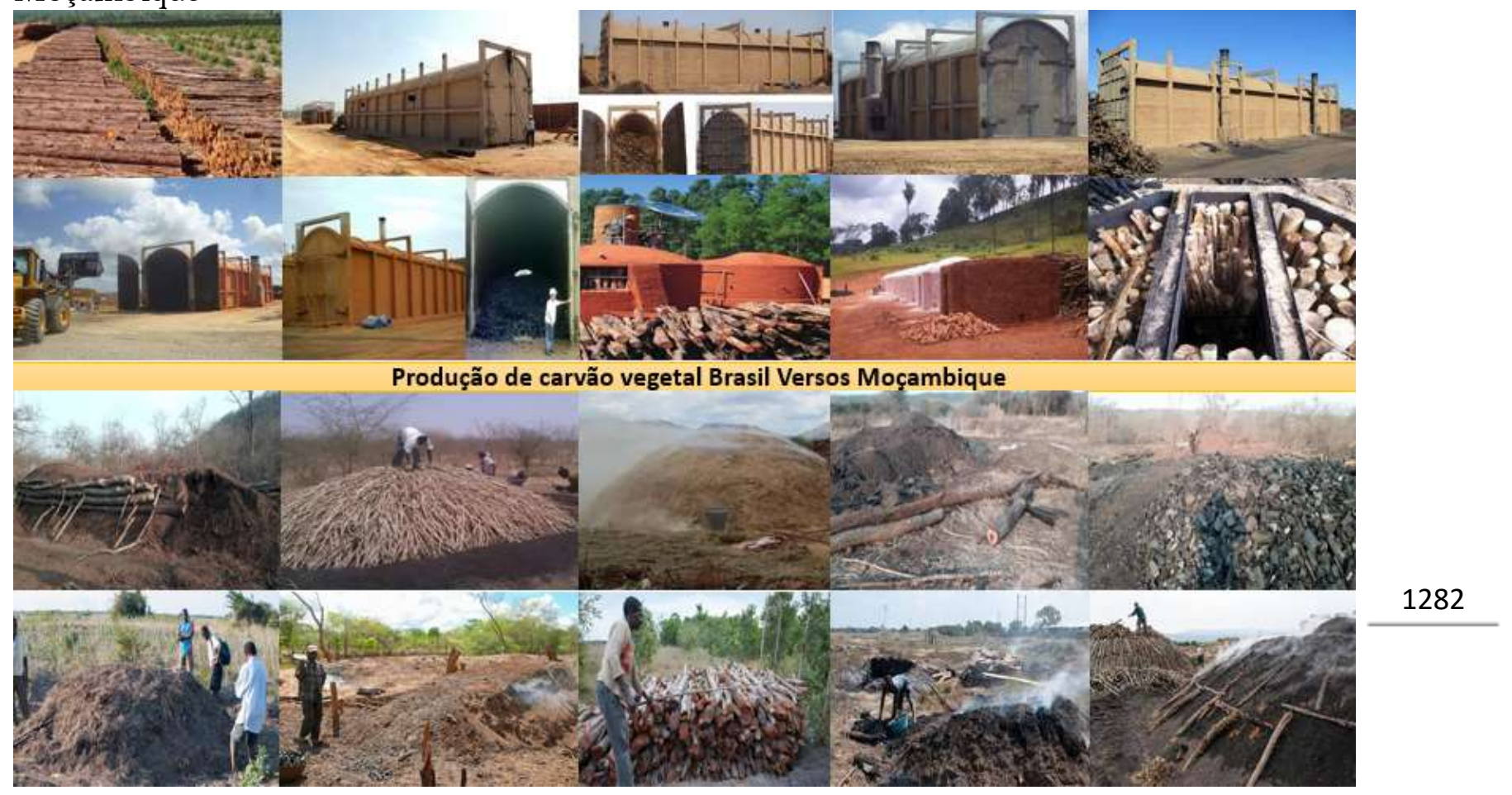

\subsection{Aplicação da Matriz de FOFA/SWOT}

A partir da Matriz FOFA, que é uma ferramenta usada para a realização de análise de ambiente e serve de base para planejamentos estratégicos e de gestão de qualquer atividade (MCCREADIE, 2008). A SWOT serviu para posicionar e verificar a situação e a posição estratégica para produção de carvão vegetal em Moçambique, adotando o modelo de produção usado no Brasil para reduzir os diversos impactos advindos do modelo de produção por via de estufas correntemente usado.

Nesta analise, considera-se quatro fundamentais variáveis que nos permitiram tomar o posicionamento de proposta de adoção do modelo de formos e florestas plantadas em Moçambique. Através destas quatro variáveis, fez-se a inventariação das forças e fraquezas 
dos dois modelos de produção, das oportunidades e ameaças dos impactos provocados por cada modelo, ambientalmente, socialmente e economicamente. Observou que os pontos fortes do modelo de produção brasileiro estão alinhados com os fatores críticos de produção, satisfazendo as oportunidades de eficiência produtiva e impactos reduzidos, o que torna o modelo por certo, melhor que o moçambicano, tornando-o ideal para propor como potencial para substituição a curto prazo do utilizado em Moçambique. Nas Figuras 4 e 5, observe-se as matrizes i e 2, Brasil, Moçambique respetivamente, fazendo uma análise ilustrada das variáveis expressando a força, oportunidades, fraquezas e ameaças (FOFA) em português, derivado da sigla em Inglês SWOT que é o acrônimo para Strengths, Weaknesses, Opportunities and Threats (ARAÚJO et al, 2015).

Fig. 4 Matriz FOFA do modelo de fornos de produção de carvão vegetal no Brasil

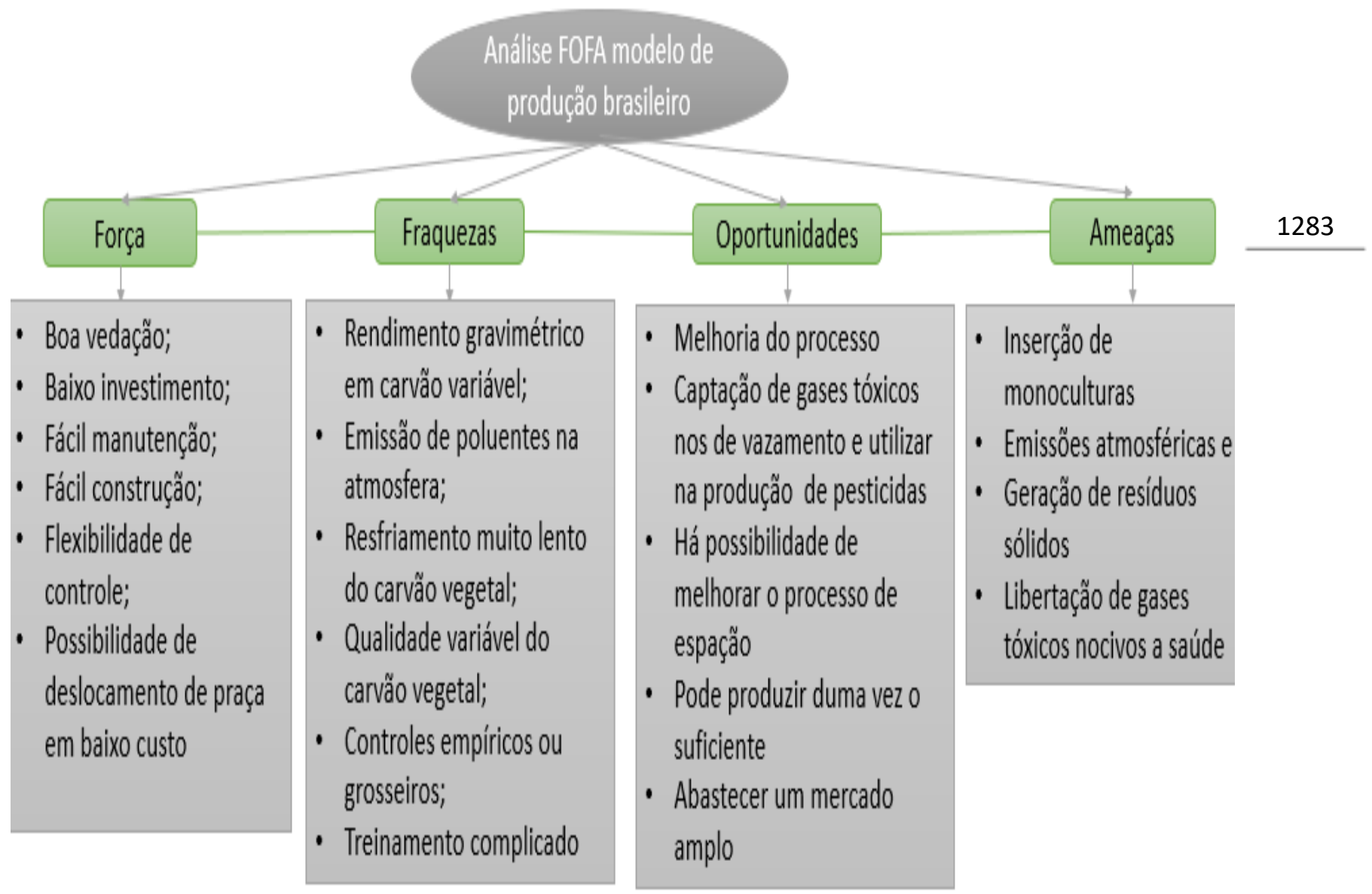


Fig. 5 Matriz FOFA do modelo de estufa de areia de produção de carvão vegetal em Moçambique

\section{Análise FOFA modelo de}

\section{produção moçambicano}

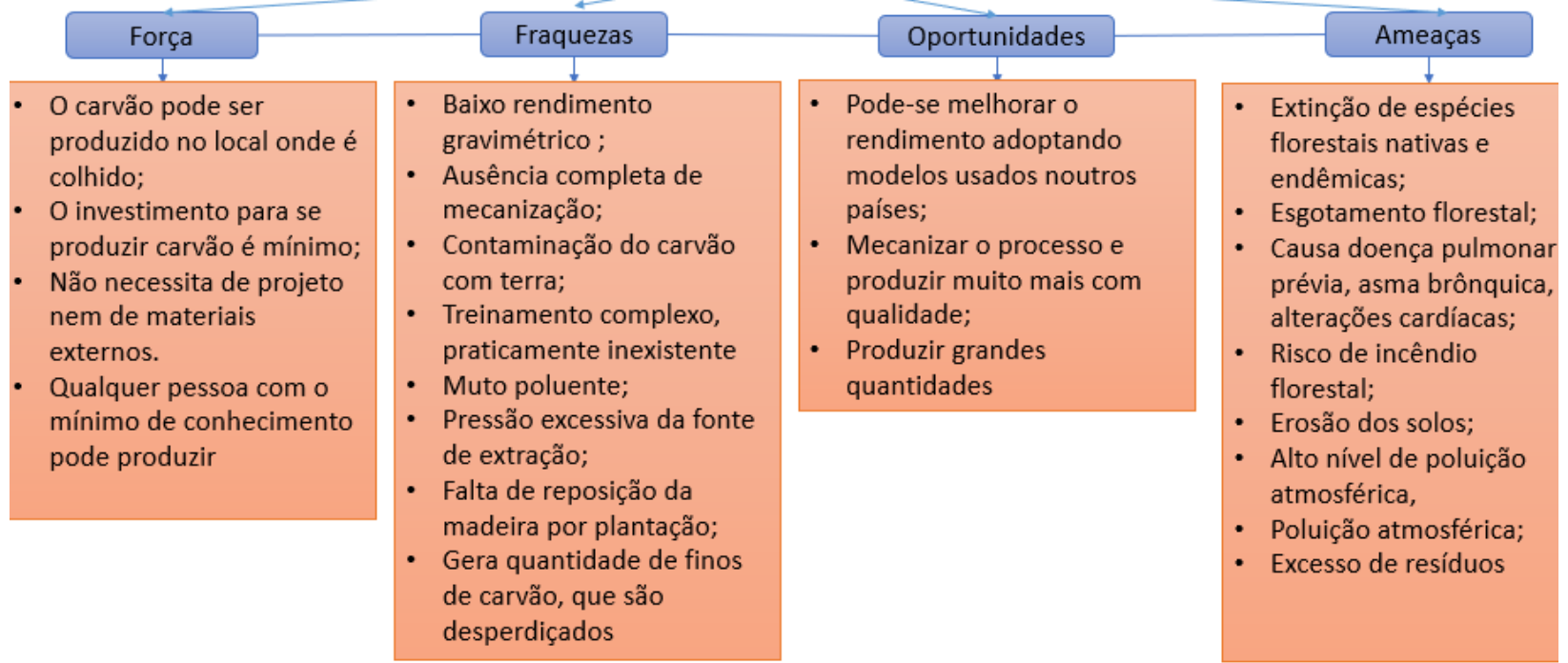

\section{RESULTADOS E DISCUSSÕES}

Com a comparação estabelecida por meio de uma metodologia simples, clara e evidente por via de esquemas representando o modelo de produção de ambos, uma grelha de imagens ilustrando as duas distintas realidades e por fim uma análise de variáveis FOFA, foi possível chegar aos seguintes resultados:

\subsection{Resultados}

RI: A técnica de produção de carvão vegetal usada em Moçambique é arcaica e figura-se insustentável sob ponto de vista ambiental, econômico e social por:

- Representar um risco de ocorrência de incêndio pela forma como se exerce;

- Poluição atmosférica e desgaste dos solos;

- Desflorestamento irracional de espécies nativas e endêmicas se reposição

- Acumula um grande prejuízo econômico pelo elevado nível de desperdício, somados desde a extração da madeira feita de forma indiscriminada ao produto final que sai 
com elevada quantidade de finos de carvão, que constituem um grande desperdício energético quando não aproveitados, como no caso vertente;

- Baixo volume produzido, o que implica baixa rentabilidade;

- Exposição a contração de várias doenças respiratórias e acidentes de trabalho por uso de equipamentos inadequados.

- O processo é bastante moroso e ocupa bastante tempo dos produtores, deixando-lhes distantes de suas famílias por muito tempo.

R2: O modelo de produção usado no Brasil, revela-se muito mais eficiente e eficaz em relação ao usado em Moçambique, constatado por meio da analise FOFA feita nas Figuras 4 e 5, o que se revela na qualidade e quantidade do carvão produzido, demonstrando-se pelo seu poder calorifico associado a forte possibilidade de perda do produto final por má gestão do processo de carbonização, resultando em carvão quase inútil, conforme pode observar na Figura 6 comparativa.

Fig. 6 Representação do impacto da má gestão do processo de carbonização da madeira

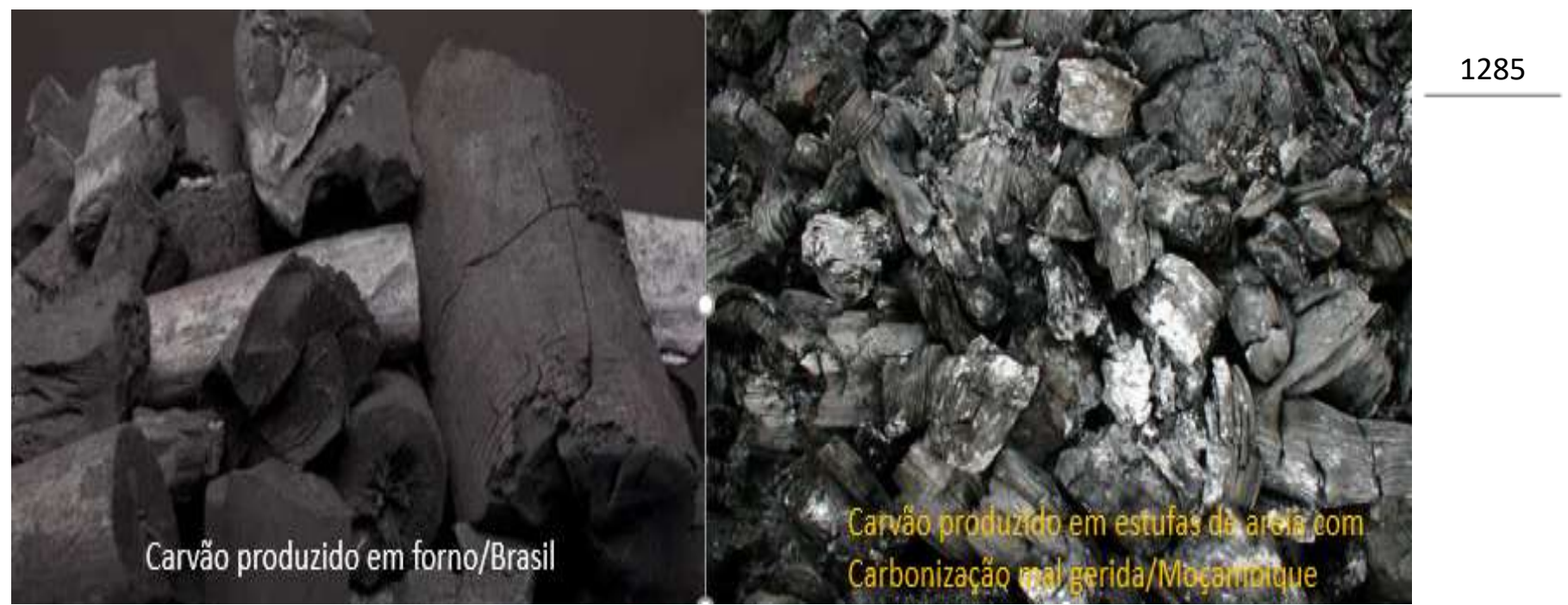

R3: O modelo de Produção de carvão vegetal em Moçambique exerce maior pressão sobre os recursos naturais, uma vez a fonte de extração de madeira para produção de carvão é a floresta nativa enquanto que na sua maioria, no Brasil, a produção de carvão é feita com recuso a madeira derivada da floresta de eucalipto plantada, possibilitando sempre a renovação na 
fonte, tornando processo produtivo mais sustentável sobe ponto de vista ambiental, econômico e social.

\subsection{Discussões}

Dr: De acordo com RODRIGUES (2017), a produção de carvão vegetal está vinculada há diversos setores, impactando a sociedade em diferentes aspectos. No contexto socioeconômico, esta atividade é caracterizada por gerar muitos empregos e renda para muitas pessoas, porém é historicamente associada a péssimas condições de trabalho (CALLE et al., 2005, apud MOURA; MARTINS, 20II). Entretanto, é uma importante fonte de geração de energia e de renda para familiares mais desfavorecidas (CARRIERI-SOUZA et al., 20I4). No que concerne a tecnologia, considerável parte da produção de carvão vegetal não apresentou evolução significativas, por várias razoes, ligados a fraca organização do setor, fraco investimento em pesquisas e apoio financeiro e técnico pelos governos. Podendo-se também mencionar o fator localizacional é descentralizada, fraco conhecimento técnico e de profissionalização, transporte do produto que, muitas vezes é realizado em veículos não

específicos para este fim (SABLOWSKI, 2008). Por sua vez, no contexto ambiental, a produção de carvão vegetal está intrínseca ao desmatamento, geração de resíduos sólidos, risco de incêndios florestais, problemas de saúde e a poluição atmosférica.

De acordo FIGUEROA et al (2012), maior porcentagem da produção de carvão vegetal no Brasil é oriunda de rudimentares fornos de alvenaria, mas com enorme tendencia ao modelo de estufas moçambicano, em que não ocorre controle de gases. O que segundo SENA et al. (2014), conota que durante o processo de produção, de toda a madeira inserida para queima, apenas 30\% é convertida em carvão vegetal, o restante da biomassa é emitido para atmosfera, aumentando a concentração de gases poluentes.

SOUZA et al. (2010), constatou que o processo de produção de carvão vegetal por natureza, requer certo número de mão de obra humana, o que expõe os trabalhadores a fumaça e calor oriunda do desse processo. Na maioria das vezes os trabalhadores na produção ficam expostos diretamente a fumaça por dias seguidos, inalando grandes quantidades de gases. Além dos 
trabalhadores, moradores do entorno também sofrem com a pratica desta atividade (CANETTIERI et al., 2013). Ainda o mesmo autor, afirma que o trabalhador está constantemente inalando gases tóxicos, produtos volatizados da queima da biomassa, fuligem, cinzas e pó do carvão. Devido a altas temperaturas dos fornos, há ocorrência de intensa sudorese corporal, podendo provocar desidratação e até mesmo queimaduras de $\mathrm{I}^{\circ}$ grau. O transporte da madeira é realizado pelos trabalhadores, que por vezes carregam peso além do correto, acarretando em possíveis lesões musculares, hérnias inguinais e escrotais.

D2: Na perspectiva de BARCELLOS et al (2007), as principais vantagens dos fornos de carvão em alvenaria de produção de carvão vegetal são: Facilidade de vedação das entradas de ar (feitas com a própria argila); Fácil controle da manobra de carbonização. Com poucos recursos facilmente se atua no controle de um forno de carvão de alvenaria; Baixo custo. Este é principal elemento que o tornou amplamente difundido no Brasil. Um forno de carvão de alvenaria tem relativamente baixo investimento inicial e boa durabilidade; fácil construção. Não é necessário nenhum projeto de engenharia complexo, eles seguem padrões de construções óbvios e simples (a exceção dos grandes fornos de carvão). A possibilidade de deslocamento da praça produtiva a baixo custo (dos pequenos fornos) acompanhando a exploração florestal; fácil manutenção. Os fornos de alvenaria precisam basicamente de tijolos e argila e um pouco de técnica e bom senso para recuperação/manutenção. Podendo-se entender das seguintes formas:

- Os fornos de carvão em alvenaria conseguem ser facilmente vedados utilizando-se argila, que é um material de baixo custo e fácil aquisição. As partes móveis dos fornos, como controladores de ar (tatus ou câmaras), portas e chaminés podem ser facilmente vedadas com argila. Entretanto, essa argila exige um acompanhamento constante dos operadores e certa manutenção ao longo de todo o processo; fácil de realizar, porém necessita de monitoramento contínuo;

- Com poucos recursos facilmente se atua no controle de um forno de carvão de alvenaria. O controle da condução da carbonização de um forno de carvão de alvenaria pode ser feito basicamente com tijolos, pedaços de tijolos e argila. Tecnicamente, não é o mais recomendado 
a se fazer pois trata-se de um controle grosseiro de processo, pouco refinado, porém um controle que funciona.

- $\mathrm{O}$ investimento em fornos construídos com tijolos é geralmente baixo. $O$ único tipo de forno que possui um custo inferior ao forno de alvenaria é o forno de terra. Entretanto o forno de terra é uma tecnologia muito rudimentar que apresenta problemas de conversão (madeira em carvão) e de operacionalidade. Um forno caipira de alvenaria é construído basicamente com tijolos, argila e água. Nada mais! E funciona!

- Primordialmente, os fornos de carvão em alvenaria são fáceis de serem construídos. Geralmente os fornos em alvenaria tem formatos simples, sendo que, possuem formas circulares ou formas retangulares. Os fornos circulares, pelas dimensões menores e forma arredondada, tendem a ser autoportantes, dispensando uso de estruturas para sustentar o forno. Um ponto de destaque são as copas esféricas destes fornos que reforçam o conceito de auto portabilidade.

- Primeiramente, como os fornos são feitos de tijolos com argila, basta desmanchar o forno e levar os tijolos para outro local onde possa ser reconstruído. Desconstruir um forno não é complicado, uma vez que os tijolos são unidos por argamassa de argila de baixa resistência. Dessa forma o custo de transporte de madeira pode ser diminuído ao levar os fornos para próximo da madeira.

- Como o forno é construído basicamente de tijolos e argila, a manutenção dos fornos acaba sendo também com tijolos e argilas. Com um carrinho de mão, um balde e uma pá o operador pode ir fazendo manutenções no forno antes, durante e após o processo de carbonização. Então, não é preciso nenhum treinamento técnico específico para realizar este tipo de manutenção. O forno está sempre aquecendo e resfriando. Ao aquecer ele dilata e ao resfriar ele contrai e isso pode provocar algumas rachaduras no equipamento. Algumas rachaduras no forno surgem a partir de contato físico de partes do forno com a madeira, carvão e/ou máquinas (para fornos que permitem mecanização de carga e/ou descarga). Sendo assim um tipo de manutenção é vedar as rachaduras que surgem no forno com argila. Um outro tipo de 
manutenção é a remoção do reboco de argila antigo do forno, onde deve-se reaplicar um novo reboco quando o mesmo não for mais adequado (BARCELLOS et al., 2007).

O modelo de produção de carvão vegetal usado em Moçambique possui várias desvantagens, uma vez que sempre lançam, sem qualquer controle na atmosfera, os gases advindos da sua carbonização. Sendo assim, estes gases altamente poluentes, acabam por gerar prejuízos a saúde dos trabalhadores que estão envolvidos diretamente na produção de carvão vegetal. Também, é comum a fumaça gerada pelos fornos gerar conflitos com confrontantes e vizinhos próximos do local de produção (BARCELLOS et al., 2007).

Ademais, nos locais onde se produz carvão de forma rudimentar, logicamente não possuem um sistema de controlo de qualidade e separação. Entretanto, alguns poucos produtores possuem um sistema minimamente controlado de produção de carvão vegetal, dentre eles podemos mencionar aqueles que se agrupam em produzem de forma mais organizada (CANETTIERI et al., 2013).

D3: Baseado na visão do Centro Nacional de Referência em Biomassa - CENBIO, a utilização da madeira para a produção de carvão vegetal é muitas vezes proveniente de floresta nativa, ou então decorrente da desapropriação destas para inserção de cultivos destinados a este fim. O desmatamento desordenado e intenso das florestas propicia a extinção de espécies nativas e endêmicas, a proliferação de pragas, a elevação das temperaturas locais e regionais, aumento dos processos erosivos, empobrecimento do solo, diminuição dos índices pluviométricos e assoreamento de rios e lagos (CENBIO, 2008).

Uma das principais culturas utilizadas no Brasil para a produção de carvão vegetal é o eucalipto. O plantio desta espécie causa impactos positivos e negativos, dependendo do contexto. O eucalipto se adapta a diversas regiões, com diferentes densidades pluviométricas, desde $400 \mathrm{~mm}$ a $1200 \mathrm{~mm}$ anuais. Referente aos lençóis freáticos é preciso observar a profundidade destes, pois as raízes de eucalipto podem atingir até 2,5 $\mathrm{m}$, podendo alcançar lençóis freáticos de baixa profundidade, sugando-os, para além de permitir a renovação da fonte e garantir a integridade da floresta nativa e extinção por conta de exploração irracional, sobre tudo em Moçambique (VITAL; PINTO; 2009). 
VITAL; PINTO (2009), referem que no cultivo de eucalipto os nutrientes (fósforo, potássio, cálcio e nitrogênio) do solo podem ser devolvidos em até 30\% se as cascas, folhas, galhos e raízes se forem deixadas no local na hora da colheita. Se comparado a culturas como cana de açúcar, feijão, milho a floresta de eucalipto apresenta superioridade em termos de eficiência no uso de água, nutrientes e em relação á biodiversidade. A forma como é realizado o plantio desta cultura, permite a criação de corredores ecológicos interligando fragmentos de matas nativas. O cultivo de eucalipto ainda corrobora para o sequestro de carbono.

A grande importância das florestas, reside no fato de desempenham a função de armazenar carbono. Armazenam em suas árvores e solo mais carbono que o existente na atmosfera atualmente. Entretanto se cortadas liberam rapidamente boa parte do carbono para a atmosfera quando queimadas, e em processo de decomposição isso ocorre de forma mais lenta (BARRETO; FREITAS; PAIVA, 2009). Esse aspecto evidencia a urgência na qual Moçambique deve adoptar o modelo usado no Brasil, aonde as florestas de extração de madeira para fins de produção de carvão vegetal são plantas.

\section{CONCLUSÕES}

Estabelecida a comparação entre os dois modelos de produção de carvão vegetal nos dois países, Brasil e Moçambique, a partir da metodologia aplicada, pode facilmente chegar as seguintes ilações:

Moçambique usa um modelo de produção que carece de substituição pelo modelo de fornos usado no brasil por forma a reduzir os impactos e externalidades gerados pelo modelo em uso, o que garantirá a sustentabilidade nos três prismas ambientais, nomeadamente Ambiental, econômica e social.

É evidente a eficácia do modelo de produção usado no brasil em detrimento do usado em Moçambique, com vários aspetos que revelam sua inviabilidade, aspeto observado a partir da análise de variáveis obtida por meio da matriz FOFA. Mas também, a ineficácia do modelo moçambicano constata-se pela fraca qualidade do produto final produzido, carvão de baixa qualidade. 
Introduzir o modelo de florestas plantadas, usado no Brasil, poderia permitir que Moçambique preservasse suas florestas nativas de extremo valor ambiental e patrimonial em devastação, pela excessiva pressão que se exerce sobre estas. Nesse processo a extração se dá pela disponibilidade de madeira, sem nenhuma distinção.

\section{REFERÊNCIAS BIBLIOGRÁFICAS}

ALBERTO, M. M. M. A contribuição do sector florestal e faunístico para a economia do país. Maputo. 2006.

ARAÚJO, J. C. et al. ANÁLISE DE SWOT: uma ferramenta na criação de uma estratégia empresarial, Lins, 2015. V Encontro Científico e Simpósio de Educação Salesiano, Centro Universitário Católico Salesiano Auxilium, Faculdade de Lins, 2015.

BARCELLOS, Daniel Camara et al. Caracterização do carvão vegetal através do uso de espectroscopia no infravermelho próximo. 2007.

BARRETO, Luciano Vieira; FREITAS, Andréia Cristina Santos; PAIVA, Lígia Cardoso. Sequestro de carbono. Centro Cientifico Conhecer. Goiânia, Enciclopédia Biosfera, n. 7, 2009. CANETTIERI, Thiago et al. A atividade de carvoejamento e o risco a saúde da população de Rancho Novo, Caeté-MG. Revista Pegada, v. I4, n. I, 2013.

CARRIERI-SOUZA, Marina et al. Cadeias produtivas do carvão vegetal na agricultura familiar no sul do Brasil. Desenvolvimento e Meio Ambiente, v. 3I, 2014

CENBIO. Centro Nacional de Referência em Biomassa. Carvão vegetal: Aspectos técnicos, sociais, ambientais e econômicos. Nota técnica da disciplina ENE5726: Biomassa como fonte de energia - conversão e utilização. São Paulo: IEE/USP, 2008.

CONJO, Manuel Pastor Francisco. PRODUÇÃO DE BRIQUETES COM RECURSO AOS RESÍDUOS RESULTANTES DA PRODUÇÃO FLORESTAL (FINOS DE CARVÃO E PAPEL). Revista Ibero-Americana de Humanidades, Ciências e Educação, v. 7, n. 4, p. 675-692, 2021.

CONJO, Manuel Pastor Francisco et al. A IMPORTÂNCIA DO PROFESSOR RECUPERADOR NA ESCOLA PARA FAZER FACE A RETOMA DAS AULAS NO PERÍODO DE COVID-I9 EM MOCAMBIQUE (CASO DE ESTUDO MUNICÍPIO DE BOANE-BAIRRO CAMPOANE). Revista Ibero-Americana de Humanidades, Ciências e Educação, v. 7, n. 4, p. 855-868, 202I.

CHAVANA, Rosalina. Estudo da cadeia de valor de carvão vegetal no sul de Moçambique. 2014 . 
DAYCHOUW, Merhi. 4o Ferramentas e Técnicas de Gerenciamento. 3. ed. Rio de Janeiro: Brasport, 2010

FERNANDES, Agnelo dos Milagres. Análise da produção de madeira para o fornecimento sustentável de energia doméstica aos centros urbanos de Moçambique. Universidade Federal do Paraná, Setor de Ciências Agrárias, Programa de Pós-Graduação em Engenharia Florestal, Curitiba, 20I4.

FIGUEROA, M. J. M.; MORAES, P. D. Comportamento da madeira a temperatura elevadas. Ambiente Construído, Porto Alegre, v. 9, n. 4, p. 157 - 174, out./dez. 2009.

FREITAS, S.R.; TAMBOSI, L.; RIBEIRO, M. C. Introdução às ferramentas de geoprocessamento para ecologia de paisagens. São Paulo: Universidade de São Paulo - USP, 2008.

MCCREADIE, Karen. A Arte da Guerra SUN TZU: uma interpretação em 52 ideias brilhantes: I. ed. São Paulo: Globo, 2008.

MOURA, A. P.; CAMPOS, J. E.; MAGALHÃES, S. R. Melhoria da qualidade de serviço na produção de carvão no setor de carbonização: um estudo de caso. Revista da Universidade Vale do Rio Verde, Betim, MG, v. 8, n. I, 2010.

PINHEIRO, P. C. C. et al. A produção de carvão vegetal: teoria e prática. Belo Horizonte, 2006

RAAD, T. J.; MELO, V. F.; OLIVERIA, A. C. Fornos metálicos para produção de carvão vegetal. . In: III FORUM NACIONAL SOBRE CARVÃO VEGETAL. Belo Horizonte, Minas Gerais, Brasil: 22 out. 2014

RODRIGUES, Thaís Isabel. Diagnóstico ambiental da produção de carvão vegetal no município de Tabaí-RS. 2017.

RODRIGUES, Jorge Nascimento; et al. so Gurus Para o Século XXI. I. ed. Lisboa: Centro Atlântico.PT, 2005.

SABLOWSKI, A. R. M. Balanço de materiais na gestão ambiental da cadeia produtiva do carvão vegetal para produção de ferro gusa em Minas Gerais. 2008.

SANTOS, Sueli de Fátima de Oliveira Miranda; HATAKEYAMA, Kazuo. Processo sustentável de produção de carvão vegetal quanto aos aspectos: ambiental, econômico, social e cultural. Production, v. 22, n. 2, p. 309-321, 2012.

SENA, Marcelo Monteiro Fonseca et al. Potencialidades do extrato pirolenhoso: práticas de caracterização. Revista Eletrônica em Gestão, Educação e Tecnologia Ambiental, v. I8, p. 4144, 2014 . 
SANTOS, Sueli de Fátima de Oliveira Miranda; HATAKEYAMA, Kazuo. Processo sustentável de produção de carvão vegetal quanto aos aspectos: ambiental, econômico, social e cultural. Production, v. 22, n. 2, p. 309-321, 2012.

SANTOS, Sueli de Fátima de Oliveira Miranda et al. Modelo ambiental e econômico de produção de carvão vegetal. 2017.

SOUZA, Rafael Machado et al. Sintomas respiratórios em trabalhadores de carvoarias nos municípios de Lindolfo Collor, Ivoti e Presidente Lucena, RS. Jornal Brasileiro de Pneumologia, v. 36, n. 2, 2010.

VITAL, Marcos Henrique Figueiredo; PINTO, Marco Aurélio Cabral. Condições para a sustentabilidade da produção de carvão vegetal para fabricação de ferro-gusa no Brasil. BNDES Setorial, Rio de Janeiro, n. 30, p. 237-297, 2009. 